\section{Commentary: When the heart team may save the patient's heart!}

\author{
Francesco Formica, MD, ${ }^{\mathrm{a}, \mathrm{b}}$ \\ Stefano D'Alessandro, MD, FECTS, ${ }^{\mathrm{b}}$ and \\ Leonello Avalli, MD
}

In resternotomy, sternal division carries an increased risk of injury of major cardiac structures because of the presence of adhesions between the posterior aspect of the bone and the right ventricle, ascending aorta, or bypass grafts. Early mortality is higher in patients with resternotomy complicated by injury relative to patients without injury during resternotomy $(18.6 \%$ vs $6.5 \%$, respectively). ${ }^{1}$ Furthermore, injury of the ascending aorta is relatively frequent immediately after resternotomy, and such injury increases the rate of in-hospital mortality. When an unexpected major injury occurs, expeditious institution of cardiopulmonary bypass (CPB) is crucial, and the early outcome often is negatively affected by the time consumed in instituting the CPB or other "rescue" maneuvers. Preoperative imaging screenings and ad hoc protocols ${ }^{2}$ are now routinely applied to identify very high-risk patients, and such screenings represent a recognized approach for planning a high-risk operation in detail, especially when the ascending aorta is in contact with the sternum. In such a complex scenario, the conventional approach is represented by the institution of $\mathrm{CPB}$ through the femoral vessels or the right axillary artery and the femoral vein, starting with the CPB and cooling the patients [even at $\left.18^{\circ} \mathrm{C}-20^{\circ} \mathrm{C}\right]$ and finally performing the sternotomy and the adherence dissection during a variable period of circulatory arrest, with the time depending on the tenacity of tissue adhesions, the fragility of the tissue of the heart and the great vessels, the dislocation of cardiac cavities,

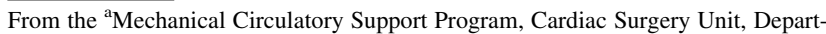
ment of Medicine and Surgery, San Gerardo Hospital, University of Milano-Bicocca, Monza, Italy; ${ }^{\mathrm{b}}$ Cardiac Surgery Unit, Cardio-thoracic-vascular Department, and ${ }^{\mathrm{c}}$ Department of Anaesthesia and Intensive Care Medicine, San Gerardo Hospital, Monza, Italy.

Disclosures: Authors have nothing to disclose with regard to commercial support.

Received for publication Oct 16, 2019; revisions received Oct 16, 2019; accepted for publication Oct 16, 2019; available ahead of print Oct 31, 2019.

Address for reprints: Francesco Formica, MD, Clinica Cardiochirurgica, Ospedale San Gerardo, ASST Monza, Via G.B. Pergolesi 33, 20052, Monza (MB), Italy (E-mail: francesco_formica@fastwebnet.it).

J Thorac Cardiovasc Surg 2021;161:1732-3

$0022-5223 / \$ 36.00$

Copyright (c) 2019 by The American Association for Thoracic Surgery

https://doi.org/10.1016/j.jtcvs.2019.10.088

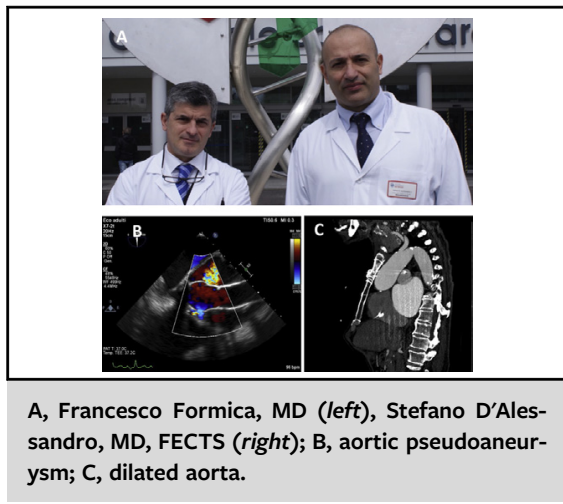

CENTRAL MESSAGE

Percutaneous cardioplegic arrest

and pulmonary venting is a

strategy that can allow a safe

surgery in complex reoperations.

The synergy within the heart

team may increase the likelihood

of survival.

and the experience of the surgeon. This is often our conventional approach. In this issue of the Journal, Mehta and colleagues ${ }^{3}$ from the Cleveland Clinic present their interesting and useful surgical approach in very complex patients who needed resternotomy. This relatively innovative approach consists of percutaneous cardioplegic arrest and percutaneous pulmonary venting before resternotomy. Since 2004, Mehta and colleagues ${ }^{3}$ have used this surgical strategy in 6 consecutive high-risk patients. Mehta and colleagues $^{3}$ deserve to be congratulated for their excellent results. All patients were discharged alive, no permanent complications were reported and, last but not least, the planned operations have been performed and completed in all patients. Apart from the attractive approach described by Mehta and colleagues, ${ }^{3}$ which is also impeccable, the strength of this study is represented by the perfect synergy of each specialist within the heart team. Refined techniques such as percutaneous endoaortic balloon occlusion, ${ }^{4,5}$ percutaneous coronary sinus catheter placement, ${ }^{6-8}$ and percutaneous pulmonary venting ${ }^{7,9}$ are safe procedures if performed by experienced anesthesiologists. Moreover, the hybrid operating room allows the surgeons, anesthesiologists, perfusionists, and nursing staff to perform these high-risk operations safely.

Together, these factors make this surgical approach as fascinating as it is safe, but it unfortunately is not achievable 
in all cardiac surgery institutions. The lack of one of the aforementioned elements, particularly the hybrid operating room, could make this already demanding surgical approach very difficult to perform or even almost impractical. It is demonstrated and recognized that a multidisciplinary team has become an integral part of the daily practice to optimize patient selection and risk-benefit ratio of particular strategies. ${ }^{10}$

In the challenging scenario described by Mehta and colleagues, ${ }^{3}$ the heart team may save the patient's heart.

\section{References}

1. Park CB, Suri RM, Burkhart HM, Greason KL, Dearani JA, Schaff HV, et al. Identifying patients at particular risk of injury during repeat sternotomy: analysis of 2555 cardiac reoperations. J Thorac Cardiovasc Surg. 2010;140:1028-35.

2. LaPar DJ, Ailawadi G, Harris DA, Hajzus VA, Lau CL, Kern JA, et al. A protocoldriven approach to cardiac reoperation reduces mortality and cardiac injury at the time or resternotomy. Ann Thorac Surg. 2013;96:865-70; discussion 870.

3. Mehta AN, Hammond B, Unai S, Navia JL, Gillinov M, Pettersson G. Percutaneous cardioplegic arrest before repeat sternotomy in patients with retrosternal aortic aneurysm. J Thorac Cardiovasc Surg. 2021;161:1724-30.
4. Malvindi PG, Margari V, Mastro F, Visicchio G, Kounakis G, Favale A, et al. External aortic-cross-clamping and endoaortic balloon occlusion in minimally invasive mitral valve surgery. Ann Cardiothorac Surg. 2018;7:748-54.

5. Murzi M, Miceli A, Di Stefano G, Cerillo AG, Farneti P, Solinas M, et al. Minimally invasive right thoracotomy approach for mitral valve surgery in patients with previous sternotomy: a single institution experience with 173 patients. $J$ Thorac Cardiovasc Surg. 2014;148:2763-8.

6. Lebon JS, Couture P, Colizza M, Fortier A, Rochon A, Ayoub C, et al. Myocardial protection in minimally invasive mitral valve surgery: retrograde cardioplegia alone using endovascular coronary sinus catheter compared with combined antegrade and retrograde cardioplegia. J Cardiothorac Vasc Anesth. 2019;33: 1197-204

7. Labriola C, Paparella D, Labriola G, Dambruoso P, Cassese M, Speziale G. Reliability of percutaneous pulmonary vent and coronary sinus cardioplegia in the setting of minimally invasive aortic valve replacement: a single-center experience. J Cardiothorac Vasc Anesth. 2017;31:1203-9.

8. Hanada S, Sakamoto H, Swerczek M, Ueda K. Initial experience with percutaneous coronary sinus catheter placement in minimally invasive cardiac surgery in an academic center. BMC Anesthesiol. 2016;16:33.

9. Avalli L, Maggioni E, Sangalli F, Favini G, Formica F, Fumagalli R. Percutaneous left-heart decompression during extracorporeal membrane oxygenation: an alternative to surgical and transseptal venting in adult patients. ASAIO J. 2011;57:38-40.

10. Holmes DR Jr, Rich JB, Zoghbi WA, Mack MJ. The heart team of cardiovascular care. J Am Coll Cardiol. 2013;61:903-7. 